\title{
Reply to: COVID-19 Digestive Symptoms Mimicking Internal Hernia Presentation After Roux-en-Y Gastric Bypass; Comment on "Internal Hernia in the Times of COVID-19: to Laparoscope or Not to Laparoscope?"
}

\author{
Rishi Singhal ${ }^{1,2}$ (D) \\ Published online: 8 May 2020 \\ (C) Springer Science+Business Media, LLC, part of Springer Nature 2020
}

\section{Dear Author:}

Thank you for writing a reply to the letter "Internal Hernia in the Times of COVID-19: to Laparoscope or Not to Laparoscope?". You have rightly stated in your reply that internal hernia is a common cause of obstruction after Rouxen-Y gastric bypass and can present with non-specific symptoms. In the pre-COVID era, most of us would have agreed that laparoscopy with/without a preceding abdominal CT would be an acceptable way to proceed if there was a reasonable index of suspicion with regard to an internal hernia. With regard to pauci-symptomatic patients, recent evidence supports that a CT abdomen on its own is a good first line of investigation and is highly accurate [1].

With the emergence of COVID, our understanding of this disease has been constantly changing and evolving. To illustrate, 7507 publications have emerged on this subject in just under 4 months [2], with 13 publications mentioning the phrase "abdominal pain" during this time. You have very rightly commented that non-specific abdominal symptoms such as anorexia, vomiting, diarrhoea and abdominal pain are not uncommon with COVID infection. It would thus be reasonable to exclude COVID infection in the differential diagnosis of abdominal symptoms for a patient with priory history of a Roux-en-Y gastric bypass.

Guidelines have been issued by most radiology and surgical societies with regard to the pre-operative role of CT chest in patients undergoing surgery. The guideline produced by the Royal College of Surgeons on the 27th of March advised the

Rishi Singhal

singhal_rishi@hotmail.com

1 University Hospital Birmingham NHS Foundation Trust, Birmingham, UK

2 Healthier Weight, Birmingham, UK use of CT chest (within $24 \mathrm{~h}$ ) or at least a chest radiograph in all patients needing emergency surgery [3]. The guidelines also suggest that "Any patient undergoing abdominal CT scan should also have CT chest". These guidelines have also been endorsed by all the other surgical Colleges and Royal College of Radiologists.

Thus, based on the diagnostic accuracy of a pre-operative CT scan of the abdomen for a suspected internal hernia in the pre-COVID era, and the recommendation of a CT chest in all patients undergoing an abdominal CT in the COVID era, we should make the case for a CT chest and abdomen as part of the standard algorithm in the investigations for abdominal pain post gastric bypass. This algorithm is a not only pragmatic but also evidence based and should reduce the risk of negative laparoscopy/laparotomy in this group of patients. I hope this view is shared by the wider bariatric community and is endorsed as a modified management algorithm for patients suspected of internal hernia in the current times. Once again, many thanks for bringing this to the attention of the bariatric community.

\section{References}

1. Bordonaro V, Brizi MG, Lanza F, et al. Role of CT imaging in discriminating internal hernia from aspecific abdominal pain following Roux-en-Y gastric bypass: a single high-volume centre experience. Updat Surg. 2020; https://doi.org/10.1007/s13304-020-00767w.

2. https://www.ncbi.nlm.nih.gov/research/coronavirus/\#datadownload. Accessed on $28^{\text {th }}$ April 2020

3. https://www.rcsed.ac.uk/news-public-affairs/news/2020/march/ intercollegiate-general-surgery-guidance-on-covid-19-update. Published on $27^{\text {th }}$ March 2020. Accessed on $28^{\text {th }}$ April 2020.

Publisher's Note Springer Nature remains neutral with regard to jurisdictional claims in published maps and institutional affiliations. 